\title{
Espaço interativo: modelo de relação universidade- empresa baseada em comunidades de prática
}

\author{
Neiva Aparecida Gasparetto Cornélio \\ Doutora em engenharia de produção pela Universidade Federal \\ de Santa Catarina (UFSC). Pesquisadora do Núcleo de Estudo em \\ Inovação, Gestão e Tecnologia da Informação (IGTI/UFSC) Santa \\ Catarina, SC, Brasil. \\ E-mail:neiva@deps.ufsc.br
}

\begin{abstract}
Aline França de Abreu
Doutora em Information Technology pela Faculty of Engineering University of Waterloo, U.W., Canadá. Professora do Departamento de Engenharia de Produção da Universidade Federal de Santa Catarina (UFSC), Santa Catarina, SC, Brasil.

E-mail: afdeabreu@gmail.com
\end{abstract}

Eliete de Oliveira Costa

Mestre em engenharia e gestão do conhecimento pela Universidade Federal de Santa Catarina (UFSC). Coordenadora Pedagógica do Complexo de Ensino Superior de Santa Catarina (Cesusc), Santa Catarina, SC, Brasil.

E-mail:eliete@egc.ufsc.br

\section{Resumo}

Este artigo apresenta a síntese de um projeto de pesquisa do Núcleo de Estudos em Inovação, Gestão e Tecnologia da Informação (IGTI) da Universidade Federal de Santa Catarina (UFSC) cujo objetivo foi desenvolver um modelo de relação entre universidades e empresas por meio de um ambiente presencial e virtual que promova a difusão da ciência, tecnologia e inovação, baseado no compartilhamento do conhecimento entre membros de uma comunidade de prática. O modelo estimula a construção do conhecimento a partir das tecnologias da Web 2.0, visando a promover o processo de transferência do conhecimento das instituições de ensino/pesquisa ao setor produtivo. A metodologia de construção deste modelo compreendeu cinco etapas: 1) fase decisória: definição do tema e delimitação do problema; 2) revisão da literatura: dividido em três temas - gestão do conhecimento, gestão da inovação e comunidades de prática; 3) diagnóstico: levantamento de informações do cenário empresarial e do núcleo de pesquisa onde se aplicou o projeto-piloto; 4) desenvolvimento do modelo, e 5) aplicação do projeto-piloto. Conclui-se que o trabalho trouxe grandes contribuições, sendo a principal o desenvolvimento de um modelo que consegue estimular a aproximação do conhecimento universitário com a prática empresarial, criando condições favoráveis à inovação.

\section{Palavras-chave}

Relação universidade-indústria. Espaço interativo. Comunidades de prática. Inovação. Gestão do conhecimento.

\author{
Interactive space: university-industry \\ relationship model based on communities of \\ practice
}

\begin{abstract}
This article presents a summary of a research project from the Innovation, Management and Information Technology Research Group (IGTI/UFSC) whose objective was to develop a model of relations between universities and enterprises through an environment that promotes the dissemination of science, technology and innovation. The model encourages the construction of knowledge from the technologies used in everyday business, to promote the process of knowledge transfer from educational/ research institutions to productive sector. The construction method of this model comprises 5 stages: 1) operative phase (definition of the subject, gathering information and defining the problem) 2) review of literature (involving the themes of knowledge management, innovation management, and communities of practice), 3) diagnostic (information-gathering about business scenario and research center where the pilot project was developed,) 4) development of the model, 5) implementation of the pilot project. The conclusion is that the work greatly contributes to develop a model that can stimulate the approach of university knowledge to business practice, creating favorable conditions for innovation.
\end{abstract}

\section{Keywords}

University-industry relationship. Interactive space. Communities of practice. Innovation. Knowledge management.

\section{INTRODUÇÃO}

Este artigo apresenta de forma sintetizada os resultados de um projeto de pesquisa desenvolvido pelo Núcleo de Estudos em Inovação, Gestão e Tecnologia da Informação (IGTI) da Universidade Federal de Santa Catarina (UFSC), cujo objetivo foi desenvolver um modelo de relação entre universidades e empresas, capaz de envolver pesquisadores, acadêmicos, profissionais de empresas e instituições 
inovadoras, bem como pessoas interessadas neste contexto. Trata-se de um ambiente interativo, presencial e virtual, denominado Espaço Interativo (EI) de discussões sobre temas específicos, busca de soluções e informações e compartilhamento do conhecimento, baseado nos preceitos de uma comunidade de prática e no âmbito virtual, fazendo uso de tecnologias da Web 2.0. Este projeto resultou em duas dissertações de mestrado e um projeto de iniciação científica (COSTA, 2009; PEREIRA, 2009; PRIM, 2009 e GLAUCO 2010).

$\mathrm{Na}$ era da modernização tecnológica, torna-se premente a necessidade de recursos humanos com conhecimentos e habilidades para atuar em tal ambiente, visto que o bom exercício da atividade profissional não está vinculado somente aos conhecimentos específicos exigidos pela atividade em si, mas também por conhecimentos e experiências desenvolvidos em alternativas paralelas. O crescente desenvolvimento e a utilização das tecnologias em todos os setores da sociedade pressupõem a importância da inclusão do ser humano em tal processo, pois, segundo Chaves (1999), desde a era primitiva, a relação com o mundo é mediada pelas tecnologias. Gasparetto (2006) ressalta que as organizações que se constituírem como organizações de aprendizagem e que descobrirem como despertar a capacidade de aprender das pessoas em todos os níveis da organização obterão sucesso e conseguirão manter-se no mercado competitivo. Ressalta ainda que o conhecimento é tão importante para o indivíduo, uma vez que reflete seu desejo de progredir, quanto o é para as empresas, dado que o saber ultrapassa fronteiras físicas, rompendo as barreiras da distância e do tempo. A necessidade de disseminação e ampliação do conhecimento humano impôs o surgimento de várias opções de mídias eletrônicas que tornam possível o acesso a um mundo de informações outrora jamais imaginado, como, por exemplo, o ensino a distância por videoconferência, internet etc.

Recursos como informação, conhecimento, redes de relacionamento e tecnologias da informação são vitais para o processo de tomada de decisão, tanto no que se refere ao desempenho inovador das empresas como para a melhoria do que oferecem, e as pessoas devem ser envolvidas neste processo. Reforçando essa ideia, recorre-se às afirmações de Toffler corroboradas por Drucker (2001) de que o conhecimento é fonte de poder, e por Nonaka e Takeuchi (1997), ao dizer que a criação de novos conhecimentos significa recriar a empresa e todos dentro dela em um processo contínuo. As universidades devem passar por ciclos de transformação e evoluir no sentido de buscar e fortalecer o relacionamento com o setor empresarial e com a sociedade. Precisam caminhar à luz das mudanças recentes, permitindo a transferência de tecnologia, elemento fundamental para a melhoria da competitividade dos processos de inovação nas empresas e, consequentemente, para a qualidade de vida.

A premissa que norteia este projeto é a de que a estruturação de uma comunidade de prática - cujo propósito é a difusão da ciência, da tecnologia e da inovação por meio de mídias presenciais e virtuais - possibilita a aproximação do conhecimento universitário com a prática empresarial. Isso favorece a inovação e pode romper possíveis barreiras que existem entre os dois segmentos.

A metodologia adotada contemplou a definição do tema e do referencial teórico que fortaleceu o desenvolvimento da pesquisa e da concepção das fases do modelo, que são explicitadas na seção 4 deste artigo. Para verificar a viabilidade de aplicação do espaço, o IGTI, constituído por equipe multidisciplinar de pesquisadores, partiu de discussões prévias em reuniões com os mentores do modelo e colocou em prática algumas das ações presenciais que dele fazem parte. Além disso, também se esboçaram as funcionalidades do ambiente virtual desejado.

O modelo de relação universidade-empresa, baseado em comunidades de prática, proposto neste estudo, justifica-se por contemplar formas e mecanismos de interação social que possibilitam abrir perspectivas para a transferência de informações científicas e tecnológicas. Esta visão é reforçada por Terra e 
Espaço interativo: modelo de relação universidade-empresa baseada em comunidades de prática

Gordon (2002) ao afirmarem que, numa época em que o aprendizado contínuo é obrigatório e as pessoas são bombardeadas com mensagens e informações irrelevantes, as comunidades de prática oferecem a seus participantes ambientes confiáveis de aprendizado e a oportunidade de contactar outros indivíduos com interesses, projetos, desafios e ou motivações similares. Na mesma linha de raciocínio, Teixeira Filho (2002) pondera que a disseminação das comunidades virtuais vem ao encontro do que é abordado na gestão do conhecimento, ou seja, o compartilhamento de experiências e informações nas organizações. Além disso, o modelo, por meio de ações facilitadoras, permite o acesso à construção do conhecimento pelas tecnologias baseadas na Web 2.0, visando a otimizar a transferência do conhecimento das instituições de ensino e pesquisa ao setor produtivo.

Este artigo se estrutura nos seguintes itens: fundamentação teórica, metodologia, o Modelo Espaço Interativo (fases de desenvolvimento e implantação e projeto-piloto), conclusões e referências.

\section{FUNDAMENTAÇÃO TEÓRICA}

A fundamentação teórica tem como propósito enriquecer o modelo desenvolvido e dar mais consistência à pesquisa. A estrutura teórica discorreu sobre três grandes temas: gestão do conhecimento, gestão da inovação e comunidades de prática e Web 2.0.

A partir destes pontos, outros subtemas se desdobraram para que questões contemporâneas fossem consideradas no modelo desenvolvido. Os temas serão abordados sob a forma de conteúdos trabalhados.

Gestão do conhecimento: foram apresentados conceitos e características, diferenças entre dados, informação e conhecimento, o processo de conversão e transferência segundo Nonaka e Tackeuchi (1997) e a estreita relação entre a gestão do conhecimento e o processo de inovação nas empresas. O tema foi tratado de forma a evidenciar que o saber ultrapassa fronteiras físicas, rompendo as barreiras da distância e do tempo, e que os avanços das tecnologias, principalmente das mídias eletrônicas, colaboram com processos indispensáveis à transformação de conhecimento em riquezas. Essa ideia é reforçada por Levy (apud GASPARET'TO, 2006) ao ressaltar que a informação e o conhecimento passaram a constar entre os bens econômicos e primordiais de uma sociedade, sendo sua principal fonte de riqueza. No entanto, neste trabalho buscou-se a superação da dificuldade em compreender o conhecimento, em especial pelo fato de ele não possuir existência física (intangibilidade) e de se dar a partir da evolução conjunta da prática com a teoria. Gasparetto (2006) afirma que a tecnologia será sempre um resultado complexo de escolhas por sujeitos sociais em situações concretas e que os computadores estão cada vez mais presentes no cotidiano social, interligando milhares de usuários no mundo inteiro. Os acessos aos meios e bens, dentro de uma sociedade, estariam se transferindo de valores materiais para valores abstratos, como o conhecimento armazenado no cérebro.Gestão da inovação: o principal ponto destacado foi a exigência de profissionais com um novo perfil devido às transformações impostas pelo avanço tecnológico. A economia centrada na era da inovação e do conhecimento requer um trabalhador capaz de pensar, decidir e de partilhar suas experiências, contribuindo para a geração de ideias e a inovação da empresa. O conhecimento humano deixa de ser visto como um produto estanque e passa a ser entendido como algo mais dinâmico. Aqui já se pode salientar a importância de desenvolver modelos que permitam o aprendizado de forma interativa, por meio de novas ferramentas e que sejam capazes de aproximar as empresas da academia. Costa (2009) observa que a base do relacionamento das universidades com empresas está nos aspectos de inovação e transferência de conhecimento entre instituições de ensino e pesquisa e demais setores empresariais, o que intensifica as inter-relações desses agentes. A capacidade de inovar das empresas é um diferencial necessário para garantir um ambiente que acompanhe as tendências e lideranças que seu 
segmento de mercado exige. Por isso a necessidade da transferência de tecnologia a partir da relação entre os setores produtivos e instituições de ensino para auxiliar na previsão de ações que garantam a sobrevivência da organização. A interação universidade-empresa é um processo que pode gerar benefícios bilaterais apesar das dificuldades desse relacionamento. Uma das principais vantagens está no fato de as universidades auxiliarem as empresas na busca por competitividade, apoiando a pesquisa e o desenvolvimento nas empresas e fomentando a inovação tecnológica.

Quanto às comunidades de prática, a maior ênfase foi dada a seus estágios de desenvolvimento e sobre o papel da tecnologia da informação, facilitando o processo de transferência de tecnologia. Segundo Wenger (1998), uma comunidade de prática não é apenas um grupo delimitado por alguma característica, mas pessoas que aprendem, constroem e fazem a gestão do conhecimento. Wenger (2002) postula que as comunidades agregam valores às organizações de diversas formas: elas colaboram na direção de estratégias, dão início a novas linhas de negócios, resolvem problemas rapidamente, transferem as melhores práticas, desenvolvem habilidades profissionais, ajudam a organização a recrutar e reter talentos etc. A participação é autosselecionada, pois as pessoas percebem quando e porque devem juntar-se àquela comunidade. Quanto à estrutura, Wenger (2001) ressalta que uma comunidade de prática possui três elementos fundamentais: a) um domínio: tema de interesse do grupo; b) a própria comunidade: interação e construção de relacionamento em torno do domínio, e c) a prática: elemento indispensável para que as pessoas aprendam no grupo como fazer as coisas pelas quais se interessam. Alguns autores relacionam a colaboração com as comunidades de prática, na medida em que são entendidas como organizações que agrupam pessoas em torno de uma temática e objetivos comuns. A colaboração é vista como um processo facilitador para a criação de comunidades e o compartilhamento coletivo do conhecimento. No entanto, para que a colaboração on-line aconteça, o participante deve sentir-se confortável com a mídia e ter segurança nela, sentir-se seguro com relação ao instrutor e aos demais colaboradores, e, por fim, verse inserido numa experiência que lhe proporcionará recompensa social.

Tema Web 2.0: focou-se no papel dessas tecnologias no suporte a comunidades de prática e na estruturação de portais de relacionamento. O termo Web 2.0 é utilizado para descrever a segunda geração da World Wide Web, ambiente on-line dinâmico, em que os usuários colaboram para a organização de conteúdo e cuja regra mais importante é o desenvolvimento de aplicativos que aproveitam as colaborações em rede para se tornarem melhores à medida são usados pelas pessoas, aproveitando assim a inteligência coletiva. As principais ferramentas da tecnologia Web 2.0 estudadas foram as seguintes: comunicadores instantâneos, como MSN Messenger $e$ Google Talk, Webmail; redes sociais, como Orkut e LinkedIn; softwares de Voip (Voz sobre IP), como o Skype; Blogs e podcasts; Wikipedia; sistemas de escritórios on-line, como o Google Docs; compartilhamento de vídeo, como o Youtube; Mashups, como um site de mapas on-line com um serviço de anúncios de imóveis para apresentar recurso unificado de localização de casas à venda; Tagging [rotulação], isto é uma maneira de vincular palavras-chave a textos ou imagens que consideram interessantes na internet, ajudando a categorizá-las e a facilitar sua obtenção por outros usuários (CA, 2007).

\section{METODOLOGIA}

Os procedimentos metodológicos formam o delineamento da pesquisa, o que - de acordo com Soares, Cosenza e Gomes (2001) - tem como objetivo disciplinar a investigação limitando o campo observando com vistas ao aprofundamento de questões levantadas, atribuindo assim maior consistência aos resultados.

No presente estudo, trabalhou-se com procedimentos de análise em uma abordagem qualitativa que, segundo Merrian (1998), envolve a compreensão de um evento em seu ambiente natural - trabalho de campo - e resulta de um ponto descritivo. Pode-se classificar a pesquisa como aplicada, porque tem 
Espaço interativo: modelo de relação universidade-empresa baseada em comunidades de prática

o intuito de gerar conhecimentos para uso prático e dirigido à solução de problemas específicos. Qualitativa porque considera haver uma relação dinâmica entre o mundo real e o sujeito, ou seja, um vínculo indissociável entre o mundo objetivo e a subjetividade que não pode ser traduzida em números. Exploratória porque visa a proporcionar maior familiaridade com o problema, objetivando torná-lo mais explícito, ou a construir hipóteses. Bibliográfica porque foi elaborada a partir de material já publicado (livros, artigos, revistas etc.).

Há que se ressaltar que o foco da pesquisa é desenvolver um modelo que permita a divulgação e o acesso à ciência, tecnologia e inovação como forma de melhorar a relação universidade-empresa e estimular pessoas interessadas neste contexto. A metodologia adotada para o desenvolvimento do modelo compreendeu cinco fases:

1. fase decisória: buscou-se definir o tema, levantar informações e delimitar o problema de pesquisa;

2. revisão da literatura: tratou-se do referencial teórico dividido em três grandes temas, 1) gestão do conhecimento; 2) gestão da Inovação e comunidades de prática e 3) Web 2.0. Os itens foram trabalhados no contexto da transferência de tecnologia e na relação entre a universidade-empresa com o intuito de fortalecer a troca de conhecimentos entre esses dois segmentos;

3. diagnóstico: trabalhou-se no sentido de busca, levantamento e investigação de informações do cenário empresarial, da sociedade e do próprio núcleo de pesquisa (IGTI) para chegar-se ao diagnóstico das necessidades empresariais e dos usuários potenciais do modelo;

4. desenvolvimento do modelo: detalharam-se as fases que compõem o modelo;

5. aplicação do projeto-piloto: descreveram-se ações presenciais desenvolvidas no projeto-piloto, e fazse o desenho preliminar do ambiente virtual em desenvolvimento pelo IGTI. A figura 1 sintetiza a metodologia utilizada.

\section{O MODELO ESPAÇO INTERATIVO - EI}

O modelo foi constituído com base na teoria pesquisada e contempla ações que permitem atender pessoas interessadas em temas específicos e empresas emprenhadas em formalizar parcerias para a solução de problemas por meio da transferência de tecnologia.

Com o intuito de balizar a construção do modelo, foram destacados alguns pressupostos tomados como verdadeiros:

- criar um espaço de interação e compartilhamento do conhecimento a partir de experiências presenciais e virtuais (como é o caso do modelo desenvolvido neste artigo) é importante para que o processo de transferência de tecnologia obtenha sucesso. Esta premissa ganha sustentação com os autores Nonaka e Kono (apud Feliciano, 2008) ao apresentarem o conceito de $b a$, ressaltando que "o ambiente para criação do conhecimento deve ser visto como um espaço de compartilhamento, que serve como uma base física ou virtual";

- Lemos (1999) ressalta a importância da interação de indivíduos no processo de busca de informações e conhecimento. O Espaço Interativo prevê um conjunto de ações que favoreçam o intercâmbio dos atores envolvidos;

- identificar e registrar os processos de criação, armazenamento, disseminação e utilização do conhecimento alinha-se com a concepção do modelo apresentado em quatro fases: diagnóstico, planejamento, desenvolvimento/execução e avaliação, detalhadas a seguir. Nonaka e Takeuchi (1997) destacam a importância do processo de conversão e transferência do conhecimento apresentado em quatro modos: socialização, externalização, combinação e internalização. Nas etapas pode-se identificar as ações que possibilitam o processo de conversão e transferência do conhecimento;

- oferecer um ambiente em que ocorra o relacionamento entre a universidade e as empresas intensifica a contribuição para estas na busca pela competitividade, apoiando a inovação tecnológica; 
FIGURA 1

Metodologia de desenvolvimento do modelo

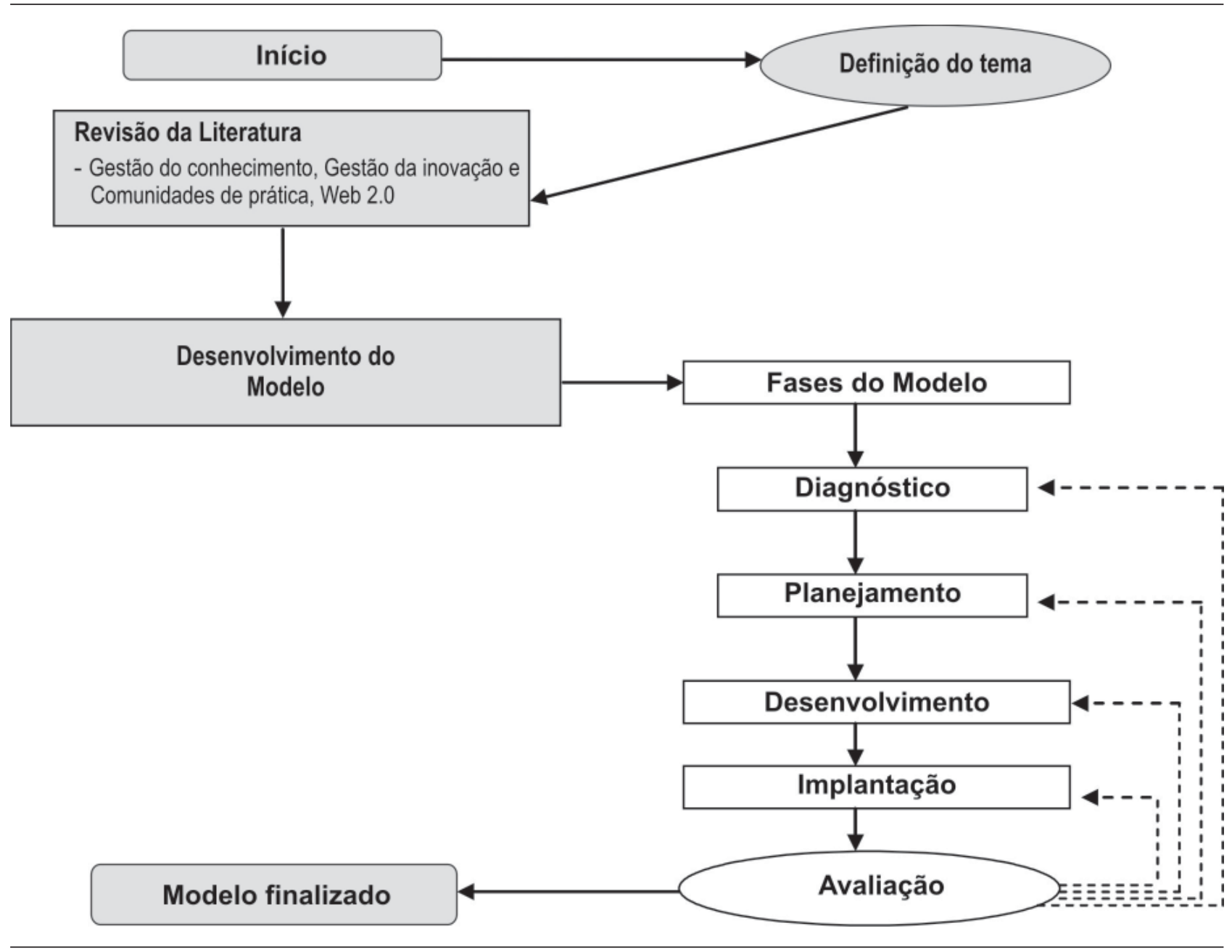

Fonte: Costa (2009)

- possibilitar às organizações o surgimento de grupos ligados informalmente pelo conhecimento permite o aprendizado coletivo, favorecendo a gestão do conhecimento empresarial. Os autores Wenger (1991), McDermott (2000), Wenger e Snyder (2001), Silva (2004), Duarte (2005) entre outros, falam sobre a importância do surgimento das comunidades de prática.

\section{Fases para construção do modelo}

1. Fase de diagnóstico: considerada fundamental para dar sustentação às etapas seguintes. Com ela se consegue chegar ao diagnóstico das necessidades das empresas, bem como dos usuários potenciais que terão acesso ao modelo. Além disso, contribui para perceber de que forma instituições de ensino e organizações podem utilizar este modelo. A primeira atividade é estabelecer um cronograma de reuniões com o objetivo de coletar o maior número de informações que permitam fazer um prognóstico para, então, chegar-se ao diagnóstico da realidade social, organizacional e do usuário potencial; a partir dessas atividades pode-se vir a estabelecer as parcerias de acordo com os interesses das partes envolvidas.

2. Fase de planejamento: aqui já é possível traçar as políticas de utilização do Espaço Interativo, bem como definir, parceiros que estejam dispostos a 
se comprometerem com as políticas adotadas. Isso se faz no primeiro momento da fase, pois é necessário conceber as estruturas do modelo. Em seguida parte-se para delinear os objetivos do projeto. A seguir são detalhados os tópicos que compõem esta fase:

a) políticas do modelo: são estabelecidas as estratégias e restrições que nortearão os planos e as linhas de ação. É por meio das políticas que se estabelecem as formas de se conduzir as ações pretendidas, assegurando a sustentabilidade do modelo:

- Como alocar recursos financeiros e quais as restrições orçamentárias para o desenvolvimento do projeto?

- Quais ações de marketing e endomarketing serão utilizadas para a divulgação do modelo junto a empresas, instituições de ensino, fundações etc?

- Como articular a fim de adquirir infraestrutura, suporte tecnológico e capacitação da equipe responsável pelas solicitações das empresas e dos acadêmicos? É ainda nesta fase que algumas questões devem ser solucionadas com cada parceria, tais como: Quem coordenará as ações do Espaço Interativo com parceiros potenciais? $\mathrm{O}$ modelo pressupõe a indicação de um coordenador que ficará responsável por todas as atividades dos participantes etc.

- Como solucionar as necessidades apontadas pelas empresas? Aqui é fundamental identificar e priorizar informações das necessidades da comunidade que está sendo formada.

- Quando funcionará o espaço? Aqui já se pode colocar em prática as normas de funcionamentos: marcar datas de início e fim de atividades tanto presenciais quanto virtuais, tais como palestras, fóruns, cadastramento das comunidades no portal etc. No caso das parcerias com empresas que firmaram convênios, pode-se inserir como a realização de cursos que atendam às necessidades identificadas no diagnóstico;
- Como serão desenvolvidas as ações? Presenciais, somente virtuais ou ambos os modos?

Ressalta-se que, além das políticas adotadas no projeto, existem as políticas internas das organizações envolvidas que também devem ser alinhadas com as do modelo;

b) objetivos: É fixar os objetivos da comunidade, os quais são decisivos para o sucesso do modelo: perfil e número de usuários cadastrados, de entidades parceiras, de cursos; do nível de aprendizagem e satisfação de usuários e empresas participantes; de horas de treinamento;

c) concepção de estruturas do modelo: Três estruturas devem ser trabalhadas: a de recursos humanos, a estrutura física e estrutura tecnológica. Estrutura de recursos humanos compreende todo capital humano necessário para a gestão e operação das ações demandadas pelo espaço, pois, para atendimento das demandas, faz-se necessária a mobilização dos integrantes e das suas funções pela interação com uma tecnologia inserida em estrutura física compatível. Neste cenário encontram-se coordenadores, gestores, monitores, técnicos, entre outros colaboradores. Para cada ator envolvido elabora-se um conjunto de ações específicas. No que se refere à estrutura física, há necessidade de que se proporcione conforto e segurança para atuação adequada dos beneficiários e das equipes pedagógica e técnica. Em eventos como palestras, fóruns, workshops, cursos e outros deve-se estar atento para que as condições do ambiente sejam adequadas, pois, do contrário, corre-se o risco do insucesso e do comprometimento de todo o trabalho realizado até então para consolidação da comunidade. Deve-se pensar no mínimo em uma sala com capacidade para que os responsáveis pela manutenção do(s) equipamento(s) possam atuar de modo confortável e em condições propícias ao bom desempenho da equipe.

Por fim, para a estrutura tecnológica, propõe-se um portal de relacionamento baseado em Web 2.0, que suporte as atividades típicas de uma 
comunidade de prática e estimule os princípios e pressupostos descritos no item 4. Alguns pontos devem ser observados como, por exemplo, definir o responsável pelas informações que deverão circular entre os usuários, visando a evitar sites que não sejam adequados aos interesses do grupo; identificar e promover o fluxo de informações, mantendo o usuário atento às situações e informações de seu interesse e da empresa por ele representada; organizar o fluxo de informações, apoiando as decisões dos gestores, de forma que, a partir das informações coletadas, sejam criadas novas diretrizes e metas de acordo com as necessidades verificadas.

3. Fase de execução: seu propósito maior é a transferência de tecnologia e o estímulo à relação universidade e ambiente empresarial. Há de se ressaltar que o Espaço apresenta propostas de natureza presencial e virtual. Como ações presenciais, preveem-se a realização mensal de encontros para apresentação de metodologias, casos, vivências e lançamento de livros ora de experiências. No ambiente empresarial, ora de pesquisas e experiências no ambiente acadêmico; promoção semestral de workshops temáticos, novamente juntando experiências da academia e do ambiente empresarial. $\mathrm{Na}$ interação virtual preveem-se as seções descritas na figura 2. Já foram concebidas as seções e telas e, nesse momento, o ambiente está sendo programado, com 30\% concebido. No anexo 1, encontram-se exemplos das telas correspondentes às seções criadas.

4. Fase de avaliação: atividade planejada com a finalidade de coletar dados úteis à solução de problemas ao processo decisório. Os processos de avaliação podem otimizar a qualidade das ações e a alocação de recursos. Deve-se considerar o plano de ações com metas e indicadores das ações de interação social, de conteúdo e de pergunta/resposta. Neste caso a avaliação ocorre no desenvolvimento de cada fase, pois se considera que desta forma o modelo é avaliado constantemente e, assim, pode-se verificar possíveis inconsistências e alterá-las quando necessário. Ressaltamos, ainda, que o modelo comporta um ambiente em que as informações e o conhecimento são apresentados de forma que atenda as necessidades de seus usuários com funcionalidades e ferramentas que valorizem a colaboração. Serão utilizados softwares disponíveis na nova concepção de internet, denominada Web 2.0.

FIGURA 2

Quadrantes definidores do ambiente do portal

\begin{tabular}{c|l|l} 
QUADRANTES & \multicolumn{1}{|c}{ DESCRIÇÃo } & \multicolumn{1}{c}{$\begin{array}{c}\text { FERRAMENTAS E } \\
\text { FUNCIONALIDADES DISPONÍVEIS }\end{array}$} \\
\hline CONTEÚDO & $\begin{array}{l}\text { Disponibilizará informações gerais sobre o } \\
\text { tema/foco do portal. }\end{array}$ & $\begin{array}{l}\text { Artigos da área, conteúdo da WIKI, } \\
\text { Nensletter IGTI News. }\end{array}$ \\
\hline \multirow{2}{*}{ RELACIONAMENTO } & $\begin{array}{l}\text { Estabelecimento de vínculos e estreitamento das } \\
\text { relações sociais com outras } \\
\text { pessoas/organizações. }\end{array}$ & $\begin{array}{l}\text { Usina de ideias, pergunte ao especialista, } \\
\text { fórum, blog. }\end{array}$ \\
\hline \multirow{2}{*}{ APRENDIZAGEM } & $\begin{array}{l}\text { Resultante da troca de conhecimento entre os } \\
\text { membros da comunidade. }\end{array}$ & $\begin{array}{l}\text { Usina de ideias, pergunte ao especialista, } \\
\text { fórum, blog . }\end{array}$ \\
\hline \multirow{2}{*}{ SERVIÇOS } & $\begin{array}{l}\text { Administração do Portal EI, divulgação das } \\
\text { atividades e usuários, promoção dos serviços. }\end{array}$ & $\begin{array}{l}\text { Área de perfil dos usuários (currículos e } \\
\text { informações sobre os usuários). }\end{array}$ \\
\hline
\end{tabular}

Fonte: Pereira (2009), adaptado do trabalho de Duarte (2005) 
Espaço interativo: modelo de relação universidade-empresa baseada em comunidades de prática

\section{Aplicação do projeto-piloto}

Para verificar a viabilidade de aplicação do modelo, realizou-se um projeto-piloto no IGTI .

O Núcleo de Inovação, Gestão e Tecnologia da Informação (IGTI) é um grupo de pesquisa voltado ao tema "inteligência para inovação", que combina as áreas de inteligência competitiva, inovação, redes sociais e engenharia do conhecimento. Está vinculado ao Departamento de Engenharia de Produção e Sistemas e aos programas de Pós-Graduação em Engenharia de Produção e Engenharia e Gestão do Conhecimento. Dentro do segundo programa, insere-se o Espaço Interativo de Ciência, Tecnologia e Inovação. Vale ressaltar que o modelo apresentado, embora contextualizado para o IGTI, pode ser aplicado em outras instituições e para outros tipos de comunidade.

\section{Resultados parciais obtidos na aplicação do projeto-piloto}

Seguindo-se os passos do modelo anteriormente descrito, apresenta-se o seguinte:

$1^{\mathrm{a}}$ - Fase de diagnóstico: inicialmente definiu-se um esquema de reuniões semanais para avaliação dos resultados. Foram apresentadas também novas ideias e sugestões sobre o desenvolvimento dos trabalhos, de modo a obter-se uma visão mais abrangente do projeto. Igualmente traçaram-se os níveis de relacionamento que seriam desenvolvidos na comunidade, definindo o acesso e a participação dos usuários. Considerada a fase inicial do modelo, a partir das experiências vivenciadas no núcleo de pesquisa (IGTI) e também de outros projetos, a equipe responsável buscou identificar as necessidades dos usuários potenciais. Com o levantamento desses dados, foi possível evidenciar o desenho geral do projeto-piloto, apresentado na figura 3.

$2^{\mathrm{a}}$ - Fase de planejamento: sendo possível estabelecer políticas de utilização com base no levantamento das necessidades e alicerçados pelo embasamento teórico, buscaram-se formas de estruturação do modelo. Foram definidas ações de caráter presencial e virtual, visando à interação e cooperação entre a universidade-empresa, foco deste trabalho. Nesta fase, almejando alocar recursos financeiros para o desenvolvimento do projeto, firmaram-se convênios e parcerias com empresas atuantes na área de inovação tecnológica e transferência de tecnologia. Também foram realizadas buscas de apoio e parcerias via editais lançados pelo Ministério da Educação e outras instituições. Por meio do Boletim IGTI News, articulouse a divulgação do modelo para empresas e em eventos da área. A partir de um banco de dados, o boletim foi enviado por e-mail, sendo assim apresentado a maior número de possíveis usuários. Foram estabelecidas parcerias com as empresas Associação de Usuários de Informática e Telecomunicações (Sucesu) e Centro de Informática e Automação de Santa Catarina (Ciasc), que ao conhecerem a iniciativa, entenderam que o modelo tem condições de atender à necessidade de oferecer serviços que darão suporte ao processo de inovação nas empresas associadas.

$3^{a}$ - Fase de execução: executadas as ações presenciais previstas. Como resultado parcial obtido com o Espaço Interativo de Ciência, Tecnologia e

\section{FIGURA 3}

Definições do espaço interativo

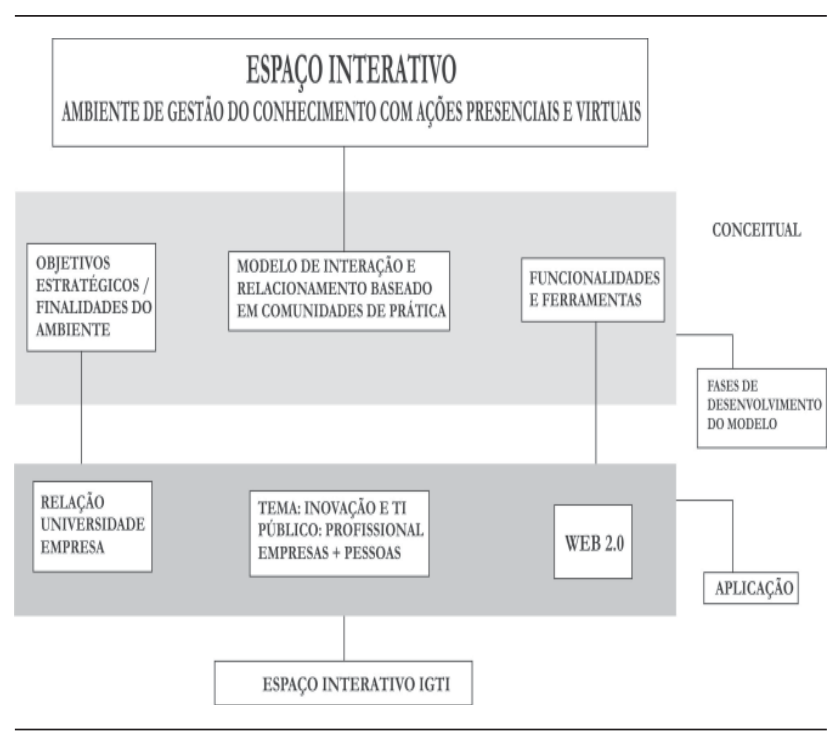

Fonte: Equipe do projeto/ IGTI (2009) 
Inovação, promoveram-se eventos como Meeting IGTI - Artefactu, a realização de Fóruns SUCESU - UFSC e a publicação do boletim IGTI NEWS, conforme detalhado na figura 4.

$4^{\mathrm{a}}$ - Fase de avaliação: os usuários, em sua maioria, são pesquisadores interessados nos temas debatidos ou empresários que veem na universidade o acesso ao conhecimento que necessitam, para aplicá-los em sua empresa. Durante esses encontros foram promovidos momentos de interação e compartilhamento do conhecimento, produzindo assim, novas práticas no contexto da comunidade.

\section{CONCLUSÃO}

Neste estudo, registraram-se algumas contribuições dos vários segmentos envolvidos. A principal foi a do próprio desenvolvimento do modelo ESPAÇO INTERATIVO - Modelo de relação universidadeempresa baseado em comunidades de prática, pois entende-se que toda alternativa que tenha o objetivo de encurtar a distância entre a comunidade acadêmica e o meio empresarial deve ser encarada com seriedade para que participantes possam continuar apresentando novas alternativas ao processo de inovação. Além disso, o modelo consegue também estimular a aproximação do conhecimento

FIGURA 4

Detalhamento das ações presenciais executadas no projeto-piloto

\begin{tabular}{|c|c|c|}
\hline Ações & Objetivos & Exemplo \\
\hline Meeting IGTI-Artefactu & $\begin{array}{l}\text { Esta série de eventos tem } \\
\text { como foco e objetivo } \\
\text { estabelecer um espaço } \\
\text { dialógico entre a comunidade } \\
\text { de pesquisadores e os } \\
\text { representantes das empresas } \\
\text { voltadas à TI e Inovação. }\end{array}$ & $\begin{array}{l}\text { O primeiro evento trouxe para a universidade } \\
\text { um empresário para falar sobre "Planejamento } \\
\text { Estratégico para atuação na Internet". } \\
\text { O segundo evento levou para um fórum } \\
\text { empresarial (empresa estadual de processamento } \\
\text { de dados) pesquisador do IGTI para falar sobre } \\
\text { sistema de inteligência para organizações } \\
\text { públicas. }\end{array}$ \\
\hline $\begin{array}{l}\text { Fórum de Governança } \\
\text { em TI - SUCESU/SC - } \\
\text { IGTI/UFSC }\end{array}$ & $\begin{array}{l}\text { Desmistificar o tema para } \\
\text { empresários do setor e, em } \\
\text { especial, os gestores de TI de } \\
\text { pequenas e médias empresas. }\end{array}$ & $\begin{array}{l}\text { Esse evento vem sendo realizado anualmente } \\
\text { desde 2006, com apoio da Fapesc. }\end{array}$ \\
\hline $\begin{array}{l}\text { Fórum de Inovação- } \\
\text { SUCESU/SC e } \\
\text { IGTI/UFSC }\end{array}$ & $\begin{array}{l}\text { Tratar do tema inovação em } \\
\text { geral e em especial com o } \\
\text { apoio de TI. }\end{array}$ & $\begin{array}{l}\text { Evento realizado anualmente desde } 2006 \text {, com } \\
\text { apoio da Fapesc e CNPq. Algumas edições } \\
\text { tiveram apoio do Senai/SC e Correios- Diretoria } \\
\text { Regional de SC. }\end{array}$ \\
\hline $\begin{array}{l}\text { Boletim Informativo } \\
\text { IGTI NEWS }\end{array}$ & $\begin{array}{l}\text { link institucional do Espaço } \\
\text { Interativo. }\end{array}$ & $\begin{array}{l}\text { Publicação mensal, o boletim traz informações } \\
\text { relevantes sobre os projetos desenvolvidos, } \\
\text { artigos atualizados, agenda de eventos, indicação } \\
\text { de artigos e livros, além de entrevistas com } \\
\text { profissionais e pesquisadores da área. }\end{array}$ \\
\hline
\end{tabular}

Fontes : as autoras 
Espaço interativo: modelo de relação universidade-empresa baseada em comunidades de prática

universitário com a prática empresarial e vice-versa, criando condições favoráveis à inovação e ao encurtamento das distâncias que existem entre esses dois segmentos. No que tange ao ambiente virtual, este encontra-se ainda em fase de desenvolvimento, com 30\% programado. Contudo, exemplos de funcionalidade e telas já foram apresentados em fóruns de pesquisadores e empresários para feedback.

Percebeu-se ao longo da realização do projeto-piloto que existe forte receptividade de ambas as partes de ações desse tipo e nossa estratégia foi sempre aliar competências de diferentes parceiros para obter os resultados desejados, dado que a maior dificuldade persiste na questão financeira e na manutenção da equipe de apoio a uma iniciativa como essa. No entanto, a busca por parcerias mostrou que muita coisa pode ser realizada com poucos recursos e que a iniciativa de aliar recursos e competências auxilia no processo de interação e de coesão dessa comunidade.

Por fim, vislumbram-se estudos que permitirão aprofundar esta pesquisa e a própria aplicação do modelo em outras instituições parceiras, bem como colocar em operação do ambiente virtual desenvolvido especificamente para esse fim. Sugere-se também a promoção de um espaço interativo que contemple ações direcionadas para estudantes que buscam informações em área específicas, tendo em vista que os jovens veem na internet um canal de comunicação amigável, acessível e que desperta a curiosidade.

Artigo submetido em 08/06/2009 e aceito em 19/08/2010.

\section{REFERÊNCIAS}

CHAVES, Eduardo O. C. Tecnologia na educação, ensino a distância, e aprendizagem mediada pela tecnologia: conceituação básica. Revisa da faculdade de Educação da PUCCampinas, São Paulo, ano 3, n. 7, nov. 1999. Disponível em: $<$ http://chaves.com.br/FRAMESPT/framesp.htm>. Acesso em: mar. 2005.

COSTA. E. O. Modelo de relação universidade empresa baseada em comunidades de prática: projeto Espaço Interativo. 2009. 116 f. Dissertação (Mestrado em Engenharia e Gestão do Conhecimento) - Centro Tecnológico, Universidade Federal de Santa Catarina, Florianópolis, 2009.

DRUCKER, P. F. O advento da nova organização. In: HARVARD BUSINESS REVIEW. Gestão do conhecimento. Rio de Janeiro: Campus, 2001.

DUARTE, D. C. Metodologia para desenvolvimento de portais de relacionamento de suporte a comunidades de prática: uma aplicação para a área de turismo e para pessoas com necessidades especiais. 2005. 256 f. Tese (Doutorado em Engenharia de Produção) - Centro Tecnológico, Universidade Federal de Santa Catarina, Florianópolis, 2005.

FELICIANO, A. M. Contribuições da gestão do conbecimento para as ações empreendedoras de inclusão digital. 2008. 158 f. Dissertação (Mestrado em Engenharia e Gestão do Conhecimento) Centro Tecnológico, Universidade Federal de Santa Catarina, Florianópolis, 2008.

GASPARETTTO, N. A. Modelo de inclusão digital para organizações: uma prática de responsabilidade social. 2006. 163 f. Tese (Doutorado em Engenharia de Produção) - Centro Tecnológico, Universidade Federal de Santa Catarina, Florianópolis, 2006.

GLAUCO, S. N.; ABREU, A. F. Projeto de pesquisa Espaço Interativo-(Ei!: ) desenvolvimento do portal de relacionamento como suporte e estímulo à relação universidade-empresa. Florianópolis: Pró-Reitoria de Pesquisa e Extensão Departamento de Projetos e Pesquisa, Universidade Federal de Santa Catarina. 2010.

LEMOS, J. L. Responsabilidade Social. In: FÓRUM DE RESPONSABILIDADE SOCIAL E BALANÇO SOCIAL, 2001, Porto Alegre. Anais..., Porto Alegre, 2001.

MCDERMOTT, R. Why information technology inspired but cannot deliver knowledge management. In: LESSER, E.; FONTAINE, M.; SLUSHER, J. (Eds.). Knowledge and communities. Woburn: Butterworth-Heinemann, 2000. (Resources for the knowledge based economy series).

MERRIAN, S. B. Qualitative research and case study application in education. San Francisco: Jossey-Bass, 1998. 
Neiva Aparecida Gasparetto Cornélio / Aline França de Abreu / Eliete de Oliveira Costa

NONAKA, I.; TAKEUCHI, H. Criação de conhecimento na empresa: como as empresas japonesas geram a dinâmica da inovação. 7.ed. Rio de Janeiro: Campos, 1997.

PEREIRA, R. Espaço Interativo (Ei!): o portal de relacionamento como suporte e estímulo à relação universidade-empresa 2009. 123 f. Dissertação (Mestrado em Engenharia de Produção) Centro Tecnológico, Universidade Federal de Santa Catarina, Florianópolis, 2009.

PRIM, L; ABREU, A. F; Relatório - Projeto de pesquisa empresa baseada em comunidades de prática: Projeto Espaço Interativo. Floriabopólis: Pró-Reitoria de Pesquisa e Extensão Departamento de Projetos e Pesquisa, Universidade Federal de Santa Catarina Universidade Federal de Santa Catarina, 2009.

SILVA, E. L; MENEZES, E. M. Metodologia da pesquisa e elaboração de dissertação. 4. ed.. Florianópolis: UFSC, 2005.
TEIXEIRA FILHO, J. Comunidades virtuais de prática: como as comunidades de prática na internet estão mudando os negócios. Rio de Janeiro: SENAC, 2002.

TERRA, J. C. C.; GORDON, C. Portais corporativos: a revolução na gestão do conhecimento. São Paulo: Ed. Negócio, 2002.

WENGER, E.; LAVE, J. Situated Learning: legitimate peripheral participation. New York: Cambridge University Press, 1991.

. Communities of practice: learning, meaning and identity. New York: Cambridge University Press,1998.

.; MCDERMOTT, R.; SNYDER, W. M. Cultivating communities of practice: a guide to managing knowledge. Boston: Harvard Business School Press, 2002.

; SNYDER JR., A. W. Communities of practice: the organizational frontier. Harvard Business Review, Boston, v. 75, n.1, jan./feb. 2000. 